\title{
Africanized bees, 1990-1995: Initial rapid invasion has slowed in the U.S.
}

\author{
P. Kirk Visscher D Richard S. Vetter a F. Chris Baptista
}

\begin{abstract}
Africanized honey bees (AHB) can seriously disrupt beekeeping and agricultural practices, as well as kill people. This study examines the progress of $A H B$ in the United States from their first detection in 1990 through 1995. AHB are now established in southern portions of Texas, New Mexico, Arizona and California. While the bees' northward migration has slowed dramatically in recent years, the ultimate extent of their range remains uncertain. AHB's impact on California agriculture will depend on how much of the state they colonize, and on the effectiveness of new beekeeping practices and management of $A H B$ as an urban pest.
\end{abstract}

The range expansion of the Africanized honey bee, Apis mellifera L. scutellata (Lepetelier), through the Americas has been monitored like that of no other insect. This is because it has had large impacts: killing people and livestock and dramatically changing beekeeping in the countries it has entered. News of the Africanized bee's spread has inspired exaggerated concern, with newspaper and magazine reports and even motion pictures portraying juggernaut swarms of uncontrollable, deadly stinging insects invading cities and towns.

Africanized honey bees (AHB) are the result of crossbreeding between European and African strains of honey bees by Brazilian geneticists in the 1950s. The geneticists reasoned that bees from tropical Africa might be bet- ter suited to the climate of tropical South America than the European honey bee (EHB), whose honey production had been disappointing. Africanized bees were released from the breeding program before selection was completed against the stronger defensive behavior that characterizes African bees.

The AHB has taken to its new environment with vigor. These bees have spread at remarkable rates during the four decades since their release, with the leading edge advancing up to 300 miles per year through the tropics of South and Central America. During this time a few colonies of AHB turned up in the United States mostly as hitchhikers on shipments of materials from South and Central America. The first time a swarm of $A H B$ was verified to have entered the United States on its own was in October 1990, in Hidalgo, Texas. The bees have since spread north and west through Texas and northern Mexico and are now found in all four states bordering Mexico.

Many sharply different predictions have been made as to how far the AHB will eventually spread into the United States This paper reviews the progress of the AHB in the United States through 1995.

\section{Africanized bees in the U.S. \\ Texas. The AHB was first detected in Texas in October 1990. By December of that year it was discovered in the eight southernmost counties of the state (fig. 1). In Texas, a county is quarantined after one colony of AHB is verified within its borders and is}

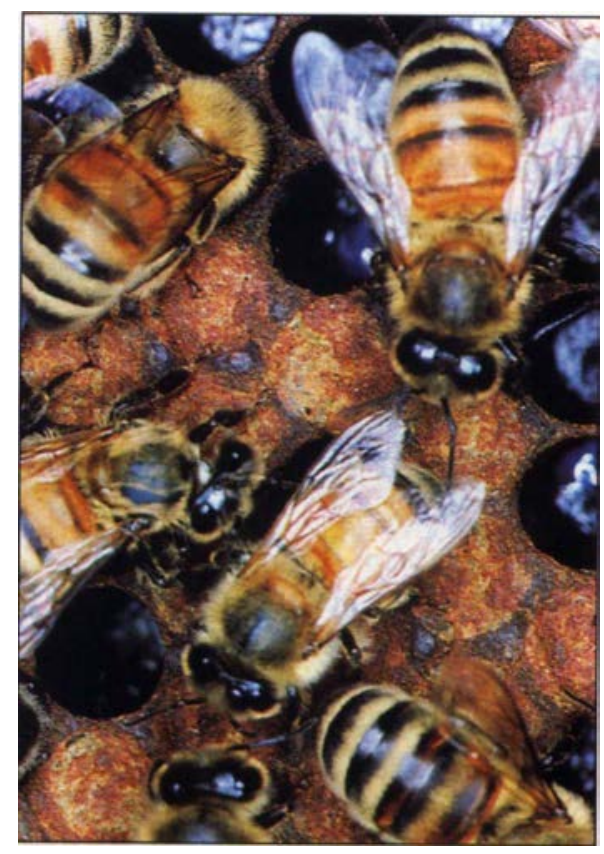

surmised to have arrived by natural migration rather than by accidental transportation. Transportation of bees out of quarantined counties requires certification that the bees are not Africanized. Counties in most of Texas are roughly square and uniform in size (unlike counties in west Texas, New Mexico, Arizona, and California), making them very convenient units for tracking AHB progress.

During 1991, 13 additional counties were declared quarantined, 30.were added in 1992, and 19 more in 1993. In 1994 and 1995, six and nine additional counties, respectively, became quarantined. In these last 2 years, however, most expansion was into neighboring counties to the east and west of those already quarantined, rather than northward.

The first death in the United States attributable to AHB occurred in Texas on Aug. 15, 1993, when an 82-year-old man attempted to burn a colony out of a house and was stung $\mathbf{4 0}$ times. The second fatality occurred on June 11 , 1994, when an AHB colony was disturbed by a lawn mower. As the mower operator ran to escape, he passed by a 98 -year-old man, who received about 50 stings and died 2 days later. These cases are unusual because for an adult in good health to die from the venom itself (rather than from an allergic response or heart attack pre- 
Africanized honey bees on comb.

$\checkmark$ A honey bee sting

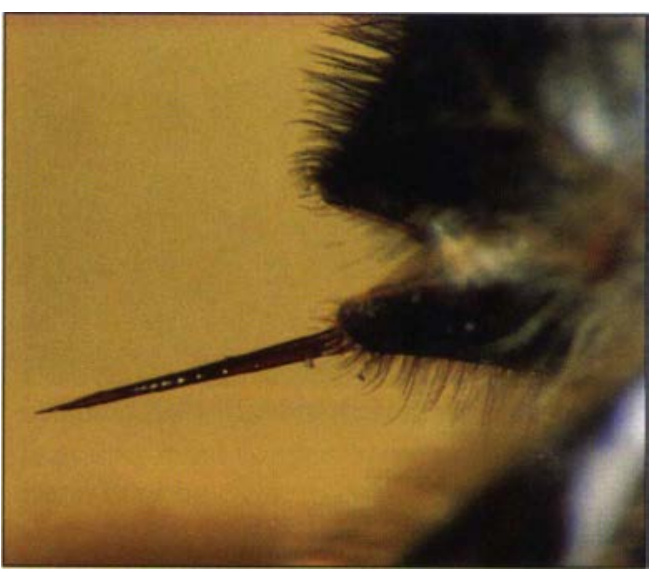

cipitated by the attack) usually requires more than 300 stings. Some people have survived more than 1,000 stings. These two deaths highlight the fact that elderly people and children are most at risk from bee attacks.

New Mexico. AHB entered New Mexico in October 1993, arriving first in the southwesternmost county (Hidalgo), most likely from Mexico. Since that time, AHB have been found throughout the southernmost part of New Mexico in the counties bordering Mexico and Texas, with the exception of Otero County. The northernmost AHB find in New Mexico was near the town of Garfield, about 30 miles northwest of Las Cruces. There are relatively few personnel involved in surveying for $A H B$ in New Mexico, and information comes mostly from the more populated areas. Therefore, AHB colonies may be present in sparsely populated areas without being detected. Differences in survey efficiency, rather than AHB abundance, probably account for the abrupt narrowing of the reported range between Arizona and New Mexico.

Arizona. AHB were first detected in Arizona when a colony, established in the roof of a Tucson house, stung a small dog to death on June 6, 1993. Experienced beekeepers and federal and state scientists who examined the remains of the colony estimated that it

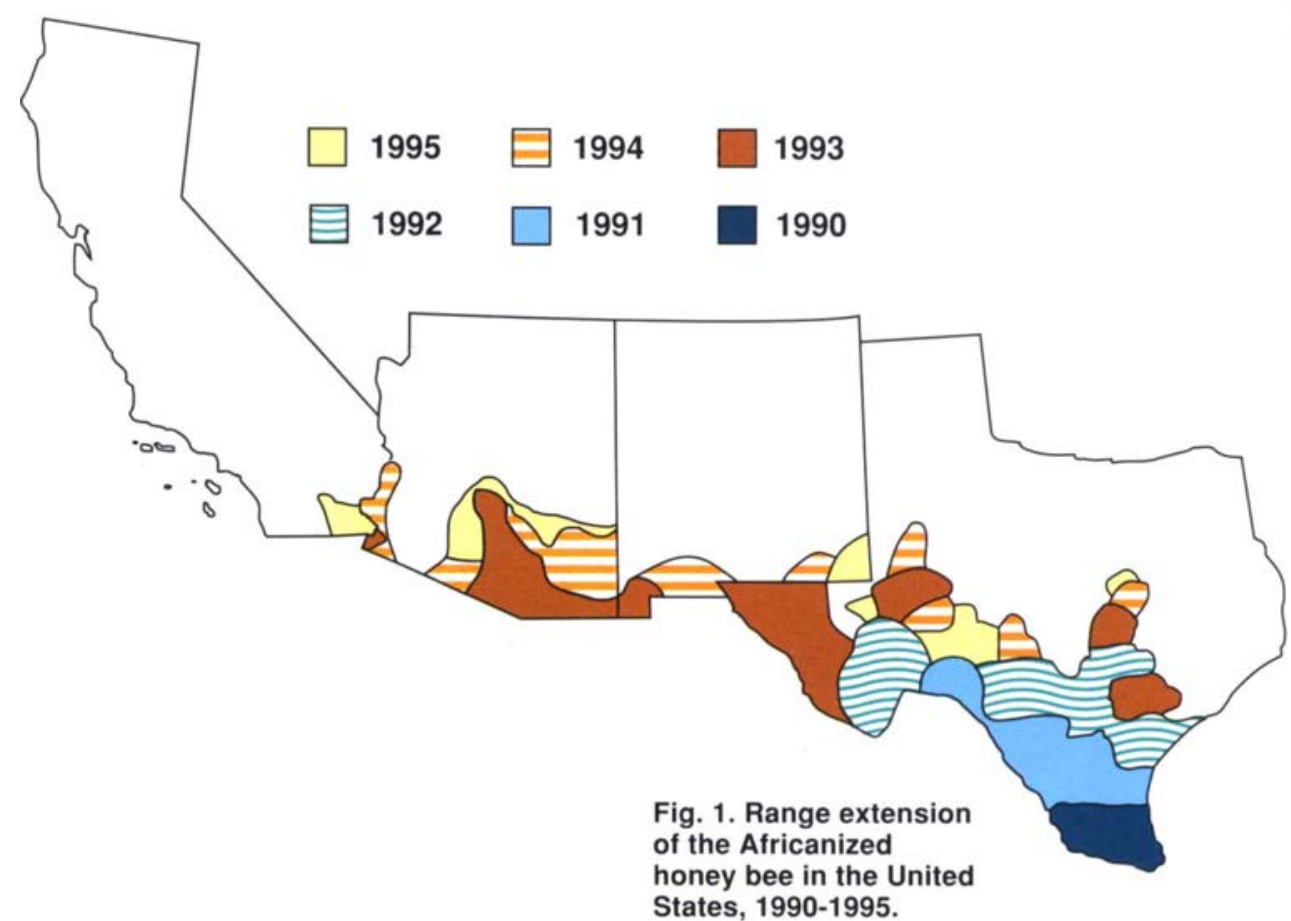

was between 4 and 8 months old, placing the bees' arrival in the state as early as October 1992. On Oct. 9, 1993, another colony was found in Peoria (west of Phoenix) when three dogs were fatally stung and several people received large numbers of stings.

By the end of 1993, the Arizona Department of Agriculture (ADA) had recognized $57 \mathrm{AHB}$ colonies from central and southern Arizona (34 feral colonies, mostly in and around homes; 22 swarms in ADA traps; and one beekeeper's hive). Ten of the AHB colonies detected were involved in stinging incidents, but no human fatalities occurred. In 1994, there were 27 additional AHB detections and 11 additional stinging incidents, but the bees' range had not expanded very much, except northward along the Colorado River to near the small town of Poston. On June 30, 1995, when ADA's AHB program ended due to lack of funding, $95 \mathrm{AHB}$ colonies had been detected, 28 of which were involved in stinging incidents.

The first human fatality from AHB in Arizona occurred east of Phoenix on Oct. 6, 1995, when an 88-year-old woman was stung more than 1,000 times. The second fatality, a 66-yearold man stung approximately 130 times, occurred 12 days later, also near Phoenix. The ADA no longer traces the establishment of $\mathrm{AHB}$, though the
Tucson USDA bee laboratory and Arizona State University are continuing to study the AHB in Arizona. Stinging incidents continue to occur, sometimes resulting in animal deaths, but no additional human fatalities have been reported.

California. Once AHB reached the western border of Arizona in June 1993 , it seemed likely that they would soon appear across the Colorado River in California. Not until Oct. 27, 1994, however, was the first AHB swarm collected and identified in California. The swarm was in a prison about 20 miles west of Blythe near the Arizona border (fig. 2). The second colony was found on March 17, 1995, south of El Centro. For the remainder of 1995 , only 12 other verified colonies were found in the state: two more in Blythe, seven around $\mathrm{El} \mathrm{Centro,} \mathrm{one} \mathrm{in}$ Winterhaven, one in Calipatria, and one in North Shore - all in the southeastern portion of California. In 1996, there were additional colonies found in areas already mentioned and individual AHB foragers were collected in the desert of eastern San Diego County (though their colony was not found). There were no additional stinging incidents.

\section{Expansion slows in U.S.}

After 5 years in the United States, Africanized honey bees have made 


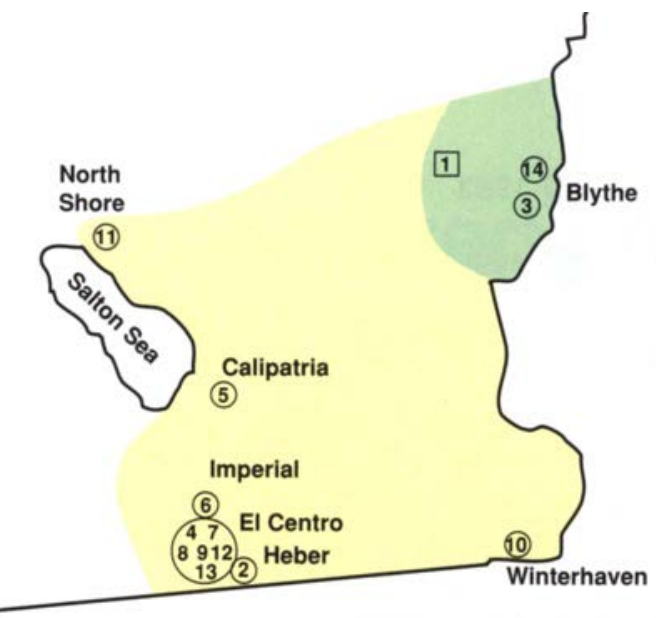

Fig. 2. Verified Africanized honey bee (AHB) finds in California. The numbers refer to chronological order in which bee colonies were found in 1994 (square) and 1995 (circles). Colony \#14 was California's only AHB stinging event and it was not fatal.

limited inroads and their northern expansion seems to have slowed dramatically. The exact reasons for this are unknown, but there are several possible explanations. Factors that may be slowing the spread of AHB include competition and genetic dilution from European bees; reaching northern limits for physiological factors, such as cold tolerance or day-length responses; parasitism by Varroa and/ or tracheal mites; local geographic barriers such as deserts and mountains; and possibly limited nesting opportunities.

It may be that in western Texas, New Mexico, Arizona, and California, regions of higher elevation and desert regions with little forage have slowed or stopped expansion of the AHB. This seems inadequate, however, to explain why the bees have not spread further into the eastern and northern parts of Texas, which have no apparent geographic barriers. In California, the AHB has been restricted to the southeastern portion of the state and has not made very strong incursions, despite a fairly wet winter in 1995, with profuse spring blooms in the desert to aid its migration.

The United States is not the first region where AHB have encountered large populations of European honey bees. Mexico had a very large beekeeping industry that seemed to pose little obstacle to the spread of the AHB. In the more temperate climate of the United States, however, EHB may

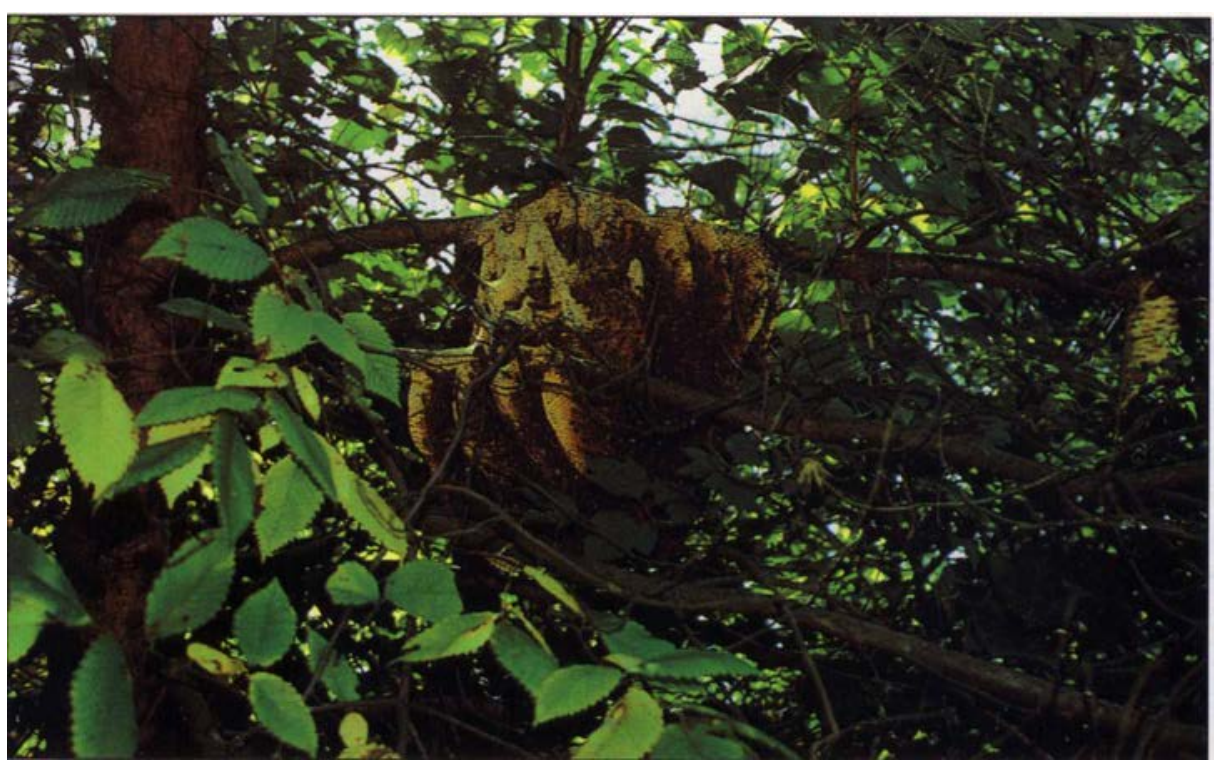

Africanlzed bees build nests in exposed locations like this more frequently than do European bees.

have a stronger competitive influence on AHB. The progress of AHB in the United States seems to be slowing at about $34^{\circ} \mathrm{N}$ latitude, which mirrors the experience of the southern hemisphere. This similarity may help to predict the ultimate range of the AHB.

\section{Predicting the range of AHB}

Africanized bees were introduced into Brazil at $22^{\circ} \mathrm{S}$ latitude, and spread both north and south. They reached their southern limits of expansion first, at approximately $34^{\circ} \mathrm{S}$ latitude in $\mathrm{Ar}-$ gentina. South of this, one finds hybrid bees intermediate between AHB and EHB, and then, further south, mostly EHB. During periods of mild weather, AHB are able to expand further south, sometimes to $40^{\circ} \mathrm{S}$ latitude or even further. This range expansion is temporary, however, and colder winters push the front of the AHB range back to around $34^{\circ} \mathrm{S}$ latitude.

Several predictions of the final range of AHB in the United States have been made, based upon various assumptions regarding the bees' tolerance for low temperatures. The most conservative of these predicts AHB will inhabit just the southern extremes of the United States, approximately the area it now occupies plus all of Florida and the southern Gulf states. Some studies, however, indicate that AHB can tolerate cold temperatures for sustained periods of time, leading other scientists to extrapolate that AHB might extend as far as the mid- latitudes of the United States, and might even survive in climates as far north as Michigan, Maine, and Canada.

Although most of these predictions rely heavily on temperature data, there are additional factors that could play a major role in limiting AHB. These might include intense competition from EHB maintained by the U.S. beekeeping industry; patterns of seasonal forage availability in the temperate zone; more extreme seasonal photoperiod changes than in the tropics and subtropics (which may affect the bees' annual cycle); and the effects of Varroa mites (which are apparently more detrimental to bees in temperate regions than in tropical regions). Until the AHB reaches the northern limits of its expansion, however, the importance of these factors will not be known.

\section{An uncertain future}

The rate of AHB expansion in the Western Hemisphere has slowed from its torrid 300-miles-per-year pace through the tropics to an almost stagnant rate in the United States. There has been very little northern movement of AHB in the last few years, and they might be reaching the limits of their northern expansion in the United States. If so, AHB may be reaching an equilibrium situation where further northern expansions will be seasonal rather than permanent.

On the other hand, the lull in movement may be only temporary. AHB ex- 
pansion may speed up again with a change in climate conditions (such as hotter or cooler summers, or wet winters), or when the population breaches geographic barriers, such as the California deserts, and reaches more favorable habitat in coastal areas with abundant bee forage and nesting sites. Such factors are not so easily invoked in the eastern range, however, where the AHB has progressed little beyond eastern Texas in the past few years.

Any specific predictions of the ultimate distribution of AHB are more likely to be proved wrong than right. Nevertheless, if AHB do not move much farther northward, then the earliest and most conservative predictions may be close to correct. Important aspects of the temperate climate conditions in the northern and southern hemispheres around $34^{\circ}$ latitude may be symmetrical and may mark the boundary between areas dominated by tropically derived AHB and areas where temperate-derived EHB dominate. These conditions could include both biotic and abiotic factors, such as temperature, photoperiod, timing of forage availability, and intensity of Varroa mite infestation.

\section{Implications for California}

AHB will probably increase in abundance in many of the southernmost agricultural areas of California. In addition, AHB will probably reach the coast in southern counties, and may thrive and expand there. Apparently, AHB infiltration into the agricultural areas of the Central Valley will occur more slowly than originally predicted, and may never be very complete. There may be a seasonal ebb and flow of AHB into the Central Valley from densely colonized areas in southern California.

Where the AHB becomes established, it has the potential to disrupt beekeeping and agriculture as currently practiced. Beekeepers are able to maintain colonies of EHB in areas colonized by AHB, but with increased costs. Finding apiary sites becomes more difficult due to public fear of Africanized bees and increased liability concerns. These factors, combined with already marginal economic con- ditions for beekeeping, will probably result in more beekeepers leaving the business, and a net loss of beekeepermanaged colonies. This is particularly unfortunate because the presence of large populations of $\mathrm{EHB}$ maintained by beekeepers is probably our best defense against AHB. European honey bees provide competition for food resources, they interbreed with AHB and dilute their genetic traits.

A reduction in beekeeping would directly affect income from honey and queen bee production. However, the impact on pollination of agricultural crops would have much greater economic significance. Growers rent bee colonies to pollinate many California crops, and many other crops also benefit from the presence of bee colonies. A reduction in beekeeping can be expected to increase the price of bee rental, and in some cases may result in a shortage of available bees, so that yields of pollination-dependent crops suffer.

The total impact of AHB on agriculture in California will depend strongly on how much of the state is colonized by these bees and the effectiveness of new management practices adopted by beekeepers. The public's reaction to AHB will also influence agriculture. Effective public and private responses to bees as urban pests - in terms of removal of unwanted bees, emergency response to stinging incidents and education - will minimize the impact of AHB. These measures would also improve public acceptance of bees and help reduce some of the negative effects of AHB on beekeeping.

Unfortunately, no one knows how much of the state will ultimately be colonized by AHB, how this colonization will affect the public in terms of stinging incidents, or how it will affect the management of $\mathrm{EHB}$ colonies. However, the colonization of the southern United States by AHB has proceeded more slowly and with less impact on public health and beekeeping than would have been anticipated by extrapolating from the experience in tropical America, and this provides some ground for optimism.

Furthermore, it is apparent that the spread of AHB in the United States is slowing down, and northward migra-

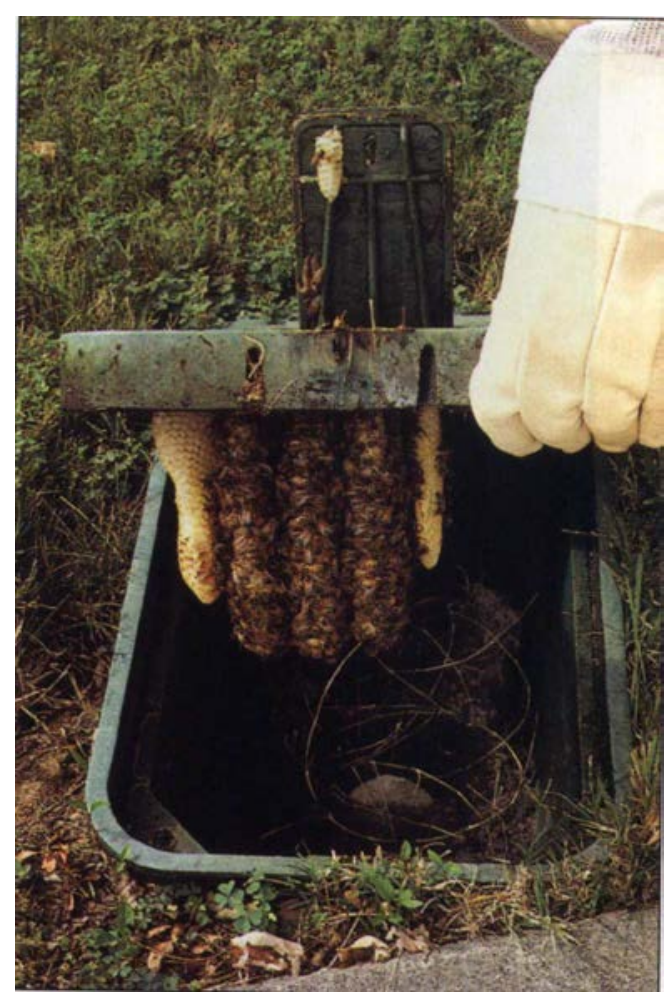

Colony of honey bees nesting in a water meter box. In areas with Africanized bees, feral colonies are more common and frequently occupy small cavities like this, which are usually unattractive to European bees.

tion in particular may be reaching an equilibrium. If so, the AHB will still affect agriculture, both in the growing regions the bee inhabits and elsewhere through its effects on migratory beekeeping and the crops that depend on it. If conservative predictions of the AHB's range in the United States turn out to be true, much of California will be spared from having to deal with $\mathrm{AHB}$, both in practical agriculture and in regulatory aspects.

In any case, the slow spread of AHB has allowed agencies and enterprises time to prepare more completely in California than they have in any other region the AHB has colonized. The impact of this preparedness on how these new arrivals affect people and agriculture will become apparent as the Africanized honey bee situation in California develops and stabilizes over the next few years.

P.K. Visscher is Assistant Professor, and R.S. Vetter is Staff Research Associate, Department of Entomology, UC Riverside; and F.C. Baptista is Entomologist, Arizona Department of Agriculture, Phoenix, $A Z$. 